mutation rate in man was between 15 and 100 rads, so the risk of genetic damage is likely to be insignificant. Were a woman of reproductive age to be treated, I would recommend application of the "10-day rule" as in diagnostic radiography to lower the risk of irradiation of a young embryo.

Court Brown and Doll ${ }^{4}$ described an increased incidence of leukaemia after irradiation for ankylosing spondylitis. This was, however, rare, with only 60 definite cases among 14554 treated. Radiotherapy for ankylosing spondylitis usually entails treatment of much haematogenous bone marrow in the spine and pelvis, unlike the areas treated in this series in which leukaemia is therefore probably not a serious risk. Steiner ${ }^{5}$ reported 12 cases of bone sarcoma developing after radiotherapy and reviewed the published cases. The given doses of radiation were much higher than that used in this series, and the overall risk appears to be very small.

I thank Professor H L F Currey for helpful advice, and Miss S Shah for preparing the typescript.

${ }^{1}$ Currey, H L F, in An Introduction to Clinical Rheumatology, ed M Mason, 2nd edn, p 244. London, Pitman Medical, 1975.

${ }^{2}$ Dewing, S B, in Radiotherapy of Benign Disease, p 55. Springfield, C C Thomas, 1965.

${ }^{3}$ Alexander, P, in Atomic Radiation and Life, p 180. Harmondsworth, Penguin, 1965.

${ }^{4}$ Court Brown, W M, and Doll, R, British Medical fournal, 1965, 2, 1327

${ }^{5}$ Steiner, G C, Cancer, 1964, 18, 603.

\section{Is penicillamine therapy in rheumatoid arthritis influenced by previous treatment with gold?}

The clinical response and side effects of both gold and penicillamine are similar. ${ }^{1}$ Gold binds to connective tissues and may remain there long after treatment has stopped. ${ }^{2}$ Penicillamine can release gold from the tissues and has been used to treat gold toxicity. ${ }^{3}$ Some of the side effects attributed to penicillamine in patients who have received gold may in fact be due to the gold itself. We have investigated whether previous gold treatment influenced the clinical response and incidence of side effects in our patients with rheumatoid arthritis (RA) who were being treated with penicillamine.

\section{Patients, methods, and results}

One hundred and fourteen patients with RA had been treated with penicillamine; 75 of these had received gold, which was stopped either because of side effects or a poor therapeutic response. In most cases penicillamine had been started within one year of stopping the gold. During treatment with penicillamine a total of 68 side effects had occurred in 50 patients. Marrow depression had occurred on nine occasions and 19 patients developed rashes. Ten rashes had occurred during the first three months of treatment and the others after the ninth month. Improvement was judged to have occurred in 56 patients.

The influence of previous gold treatment on clinical response and side effects is shown in the table. Although the incidence of all side effects was the same in both groups, marrow depression and rashes were more common in the gold-treated patients. Two patients with marrow depression had had

Influence of gold on penicillamine treatment in 114 patients with rheumatoid arthritis

\begin{tabular}{|c|c|c|c|}
\hline & & $\begin{array}{c}\text { Previous gold } \\
(\% \text { of } 75 \text { patients })\end{array}$ & $\begin{array}{c}\text { No gold } \\
(\% \text { of } 39 \text { patients) }\end{array}$ \\
\hline $\begin{array}{l}\text { Marrow depression } \\
\text { Rash . . . .. } \\
\text { All complications } \\
\text { Improvement .. }\end{array}$ & $\begin{array}{l}\cdots \\
\cdots \\
\cdots\end{array}$ & $\begin{array}{r}9 \\
20 \\
45 \\
52\end{array}$ & $\begin{array}{r}5 \\
10 \\
41 \\
54\end{array}$ \\
\hline
\end{tabular}

neutropenia when on gold, and four had had a rash. Seven patients with a rash thought to be due to penicillamine had also developed a rash with gold. One had developed alopecia, one mouth ulcers, and one neutropenia. Eight of the ten patients with an early rash due to penicillamine had been on gold treatment.

\section{Comment}

Although our observations suggest that there is no difference between the clinical response or the overall incidence of side effects with penicillamine whether patients had previously been treated with gold or not, the most important fact is that rashes and marrow depression were twice as common in the gold-treated group. Of the 15 gold-treated patients who developed a rash with penicillamine, seven had had a rash while on gold. A multicentre trial group ${ }^{4}$ reported that treatment with gold resulted in no appreciable difference in the prevalence of side effects in RA patients on penicillamine, though noting that there were more rashes in the gold-treated group. Tsang et $a l^{5}$ found that 14 of 17 patients with advanced RA who had not responded to gold improved with penicillamine. They found no correlation between the toxic manifestations of the two drugs, although two patients had mouth ulcers, one proteinuria, and one a rash with both penicillamine and gold.

Our results show that rashes, and possibly marrow depression, may be more common if patients have received gold. Theoretically, also, some of the early rashes noted with penicillamine might in fact have been caused by gold being released from the tissues by penicillamine. It would be sensible to take extra care in the supervision of patients starting on penicillamine if they have had gold treatment.

${ }^{1}$ Huskisson, E C, et al, Annals of the Rheumatic Diseases, 1974, 33, 532.

2 Block, W D, et al, fournal of Pharmacology and Experimental Therapeutics, 1941, 73, 200.

3 Davis, C M, American fournal of Medicine, 1969, 46, 472.

4 Multicentre Trial Group, Postgraduate Medical fournal, 1974, 50, suppl No $2, \mathrm{p} 77$.

5 Tsang, I K, et al, Arthritis and Rheumatism, 1977, 20, 666.

(Accepted 15 March 1978)

St Stephen's Hospital, London SW10

$M$ WEBLEY, MB, MRCP, senior registrar (present address: Westminster Hospital, London SW 1)

E N COOMES, MD, FRCP, consultant physician

\section{Synovial cyst causing an inguinal mass}

Diagnosis of a lump in the groin may be difficult and the possibility of malignancy occurring often leads to biopsy. We present two cases in which synovial cysts caused such diagnostic difficulty.

\section{Case 1}

A 69-year-old woman had had intermittent pain in the right groin for two years. She had suffered from severe rheumatoid disease for 13 years and her medication had included prednisone. During admission for elective knee surgery, examination of the right groin showed a firm fixed swelling, $3 \times 3 \mathrm{~cm}$, above the inguinal ligament and lateral to the femoral artery. It was not tender or reducible. The results of full blood count and biochemical tests were unhelpful. $X$-ray films of the right hip showed appreciable femoral head deformity with protrusio acetabuli. At surgical exploration a cyst extending posteriorly into soft tissues and containing $150 \mathrm{ml}$ dark fluid was aspirated and excised. The aspirate showed scanty white blood cells on microscopy, and culture, including that for tubercle bacilli, was sterile. Histology of the cyst wall showed only necrotic material.

\section{Case 2}

A 61-year-old woman gave a four-month history of discomfort in the right groin associated with a lump that was slowly enlarging. Her history included clinical osteoarthrosis of the left hip. Examination showed a firm mass, $4 \times 7 \mathrm{~cm}$, lateral to the femoral artery in the femoral triangle. It was 